\title{
Secretory breast carcinoma in a 66 year old man
}

\author{
Hiroko Kuwabara, Masahiko Yamane, Setsuo Okada
}

\begin{abstract}
A secretory carcinoma of the breast, associated with axillary node metastasis, unilateral gynaecomastia, and chronic active hepatitis, occurred in a 66 year old man. Although secretory carcinoma of the breast usually occurs in children and adult women, our case shows that it can rarely occur in the elderly male. (F Clin Pathol 1998;51:545-547)
\end{abstract}

Keywords: breast; secretory carcinoma; gynaecomastia

Secretory carcinoma of the breast is a rare neoplasm first described in children and called "juvenile carcinoma." "Later it was also found in female adults, although the median age (the second decade) of secretory carcinoma of the breast is younger than that of the usual breast cancer. ${ }^{2}$ On the other hand, breast carcinoma is an uncommon neoplastic condition among men, accounting for no more than $1 \%$ of all breast carcinomas, ${ }^{3}$ and to our knowledge only six secretory carcinomas of the breast have been reported, all in men less than 25 years of age. ${ }^{24-9}$ Here, we report a case of secretory carcinoma of the breast in a 66 year old man (the oldest known secretory carcinoma of the breast in a male) associated with axillary node metastasis, unilateral gynaecomastia, and chronic active hepatitis. \section{Surgery}

First Department of

M Yamane

S Okada

Correspondence to: Dr Hiroko Kuwabara, Second Department of Pathology, Kagawa Medical University, Miki-Cho,

Kita-Gun, Kagawa,

761-0793, Japan.

Accepted for publication 4 March 1998

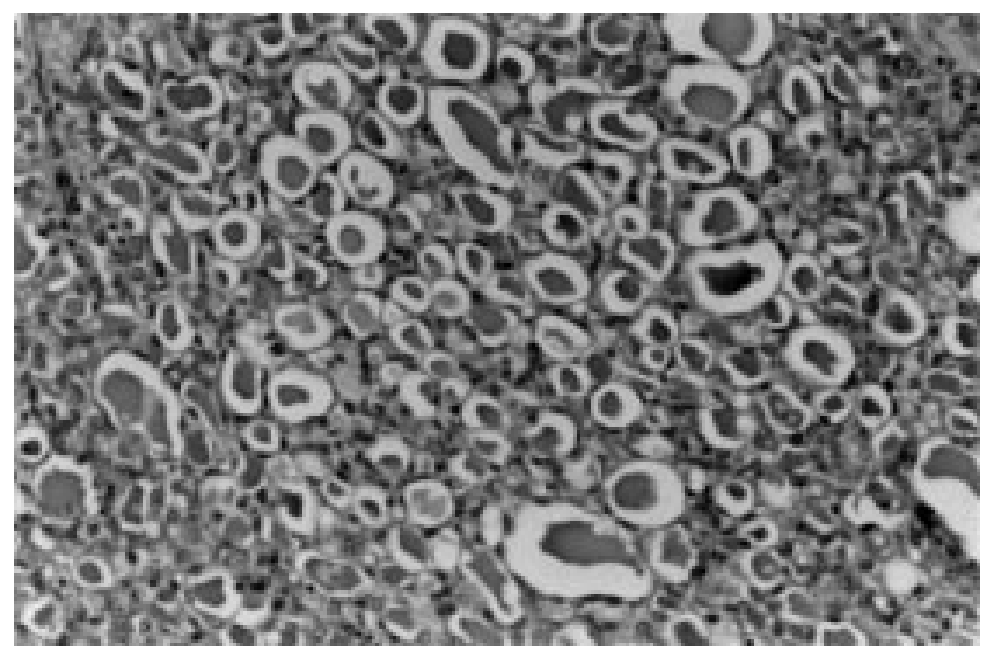

Figure 1 Breast tumour characterised by prominent microcystic secretion. A 66 year old Japanese man presented with a recently enlarging tumour in the subareolar region of the left breast. The tumour was noticed three years before and the clinical impression was of gynaecomastia as he had hepatitis $\mathrm{C}$ virus ( $\mathrm{HCV}$ ) positive chronic active hepatitis. At the ages of 62 and 65 years, he had had two operations for hepatocellular carcinoma. On the first occasion the histology was of poorly differentiated (sarcomatous) type, while on the second occasion it was of well differentiated (trabecular) type. At the time of the breast presentation, follow up examination of the liver showed a solitary tumour. Segmentectomy (S4) of the liver and removal of the breast tumour were performed simultaneously. Computed tomography and ultrasonography showed no other tumour anywhere in the body, including the thyroid. As the breast tumour showed infiltrative growth and tumour cells were present in the surgical margin, the patient had a modified radical mastectomy with axillary node dissection. The right breast had no tumour. The patient was free from local recurrence or metastases eight months after the surgery.

\section{Histological findings}

The breast tumour resected in the first operation was $3.0 \times 3.0 \times 2.6 \mathrm{~cm}$, relatively circumscribed and markedly firm, with a greyishwhite cut surface. The tissues were fixed in $10 \%$ buffered formalin. Microscopically, the tumour was separated by hyalinising fibrosis and showed partial infiltration of the margin. The tumour cell arrangement was microcystic and papillary. Tumour cells and microcystic spaces contained abundant secretion, which usually stained pale pink with haematoxylin and eosin, and they mimicked thyroid follicles (fig 1).

Immunohistochemistry was performed by

the streptavidin-biotin method using the following antibodies: keratin, epithelial membrane antigen (EMA), a lactalbumin, thyroglobulin, S100 protein, monoclonal and polyclonal carcinoembryonic antigens (CEA) (Dako, Glostrup, Denmark), gross cyst disease fluid protein (GCDFP15) (Signet Inc, Dedham, Massachusetts, USA), and progesterone and oestrogen receptor (Immunotech Inc, Marseille, France). The tumour cells were positive for $\alpha$ lactalbumin, $\mathrm{S} 100$ protein, EMA, keratin, and polyclonal CEA. Very little reactivity was observed for GCDFP15. The tumour cells were negative for thyroglobulin, monoclonal CEA, and progesterone and oestrogen receptor. The secretion was strongly PAS positive, even after diastase digestion, and was also mucicarmine positive and immunohistochemically $\alpha$ lactalbumin positive. Intraductal component including papillary growth was present (fig 2).

The liver tumour, on the other hand, was encapsulated and $1.0 \mathrm{~cm}$ in diameter. Histology revealed well differentiated hepatocellular carcinoma (trabecular type) and the surrounding tissue showed chronic active hepatitis. The 


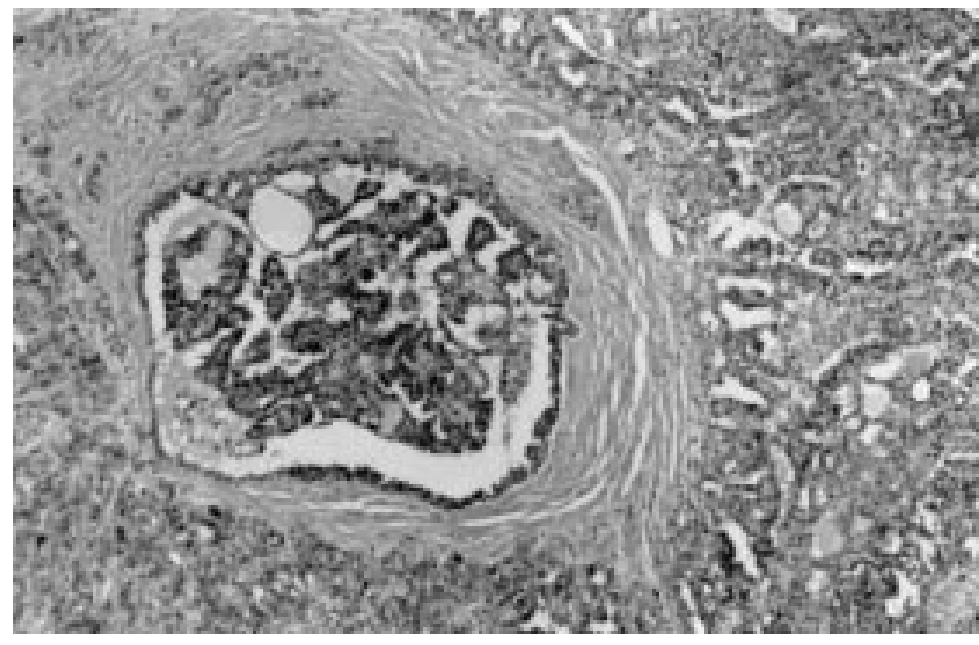

Figure 2 Intraductal carcinoma showing papillary growth (left).

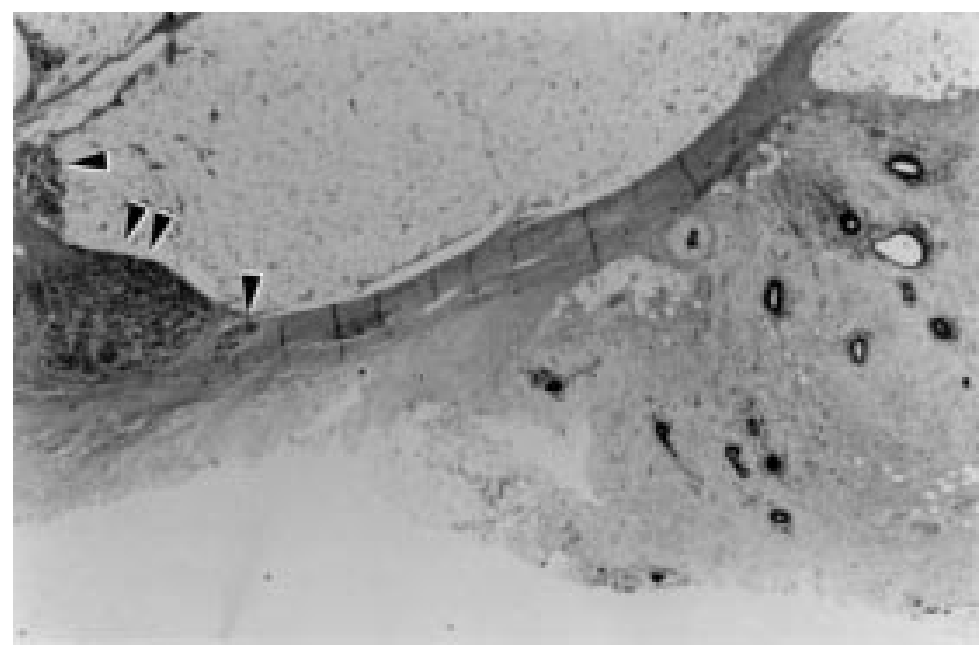

Figure 3 Gynaecomastia (right) in the second operation (arrowheads: secretory carcinoma cells): periductal oedema and cellular stroma with minimal epithelial hyperplasia.

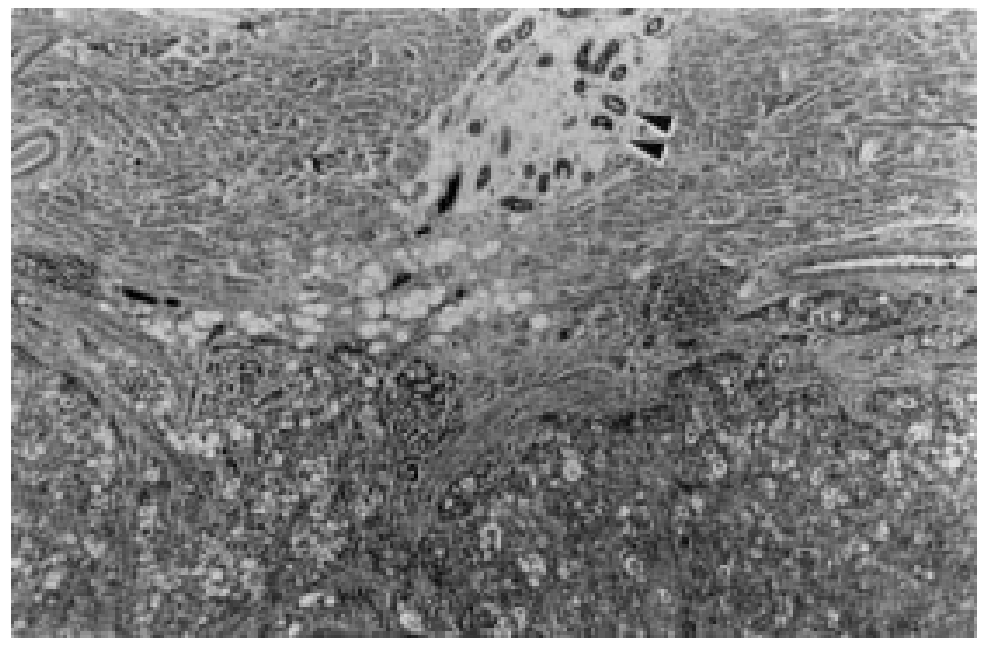

Figure 4 The relatively circumscribed tumour (arrowheads: sweat glands).

breast tumour did not resemble the liver tumour. From these findings, we diagnosed our case as secretory carcinoma of the breast. The remaining mammary ducts showed atypical hyperplastic change.

Most of the subsequently resected breast tumour $(2.0 \times 2.0 \times 1.5 \mathrm{~cm})$ showed minimal hyperplastic mammary ducts, periductal oedema, and fibrous stroma, which were histologically compatible with gynaecomastia (fig 3). The ductal epithelium of the gynaecomastia was immunohistochemically weakly positive for oestrogen receptor in the nucleus and for progesterone receptor in the membrane. The rest of the secretory carcinoma adjoined the gynaecomastia and had relatively circumscribed margins (fig 4). There was no evident transition from the ductal epithelium of the gynaecomastia to carcinoma. The left axillary two lymph nodes (brachial subscapular) showed metastasis of secretory carcinoma (fig 5).

\section{Discussion}

Secretory carcinoma of the breast is one of the least common forms of breast carcinoma, ${ }^{10}$ and most have been seen in children and adult females. In addition, six secretory carcinomas of the breast cases occurring in the male breast have been reported (table 1). All these patients except one had an excellent prognosis, as described in another report. ${ }^{5}$ Three of these cases were less than 10 year old, and the others were between 20 and 24 years old, our case being the oldest among the reported male cases. (The oldest female was $73 .{ }^{7}$ ) Tavassoli and Norris ${ }^{2}$ suggested three features that indicated a favourable prognosis in secretory carcinoma of the breast: (1) tumour size less than 2 $\mathrm{cm}$; (2) age of less than 20 years at diagnosis; and (3) circumscribed margins. Another report $^{5}$ also emphasised the importance of patient age in assessing the likely behaviour of the tumour. One male patient (24 years old, with a $4 \mathrm{~cm}$ tumour) died of tumour recurrence and metastasis 20 years later. From his age, tumour size, and the presence of axillary lymph node metastases, our case seems likely to have a relatively poor prognosis, and careful follow up needs to be undertaken.

Several risk factors for the development of male breast carcinoma have been identified, including testicular dysfunction such as orchitis, traumatic injury, radiation exposure, liver disease, obesity, and tuberculosis. ${ }^{11}$ Our patient had HCV positive chronic active hepatitis. It is well known that liver disease causes gynaecomastia because it induces a state of hyperoestrogenism. Our case showed gynaecomastiathat is, epithelial hyperplasia of ducts, periductal oedema, and densely fibrous stroma. Roth et al reported secretory carcinoma of the breast in a 23 year old man with unilateral gynaecomastia, and they noted that carcinoma preceded the gynaecomastia (his breast tumour was present when he was two years old and gynaecomastia is rare before 10 years of age). ${ }^{6}$ In our patient, there was no confirmation that the secretory carcinoma was preceded by gynaecomastia, and no evident histological transition from ductal epithelium of gynaecomastia to carcinoma. Moreover, our tumour cells were immunohistochemically negative for oestrogen and progesterone receptors. In general, there is no evidence that atypical proliferative changes in gynaecomastia are associated with an increased risk of the development of carcinoma, although carci- 
Table 1 Secretory breast carcinoma in men

\begin{tabular}{|c|c|c|c|c|c|c|c|}
\hline Author & Year & Age (years) & $\begin{array}{l}\text { Tumour size } \\
(\mathrm{cm})\end{array}$ & Location & $\begin{array}{l}\text { Axillary } \\
\text { spread }\end{array}$ & Treatment & Follow up \\
\hline Simpson $^{4}$ & 1969 & 5 & ND & ND & ND & Local extirpation & Well, 4 years \\
\hline Tavassoli $^{2}$ & 1980 & 9 & ND & ND & NE & Local excision & Well, 1.75 years \\
\hline $\mathrm{Karl}^{5}$ & 1985 & 3 & 1.5 & Subareolar & + & Simple mastectomy & $\mathrm{ND}$ \\
\hline Roth $^{6}$ & 1988 & 23 & $3.0 \times 2.0$ & Subareolar & - & $\begin{array}{l}\text { Modified radical } \\
\text { mastectomy }\end{array}$ & Well, 4 years \\
\hline Krausz $^{7}$ & 1989 & 24 & 4.0 & Upper outer & $\mathrm{NK}$ & $\begin{array}{l}\text { Simple } \\
\text { mastectomy, } \\
\text { radiotherapy }\end{array}$ & $\begin{array}{l}\text { Recurrence, } \\
\text { metastasis, and } \\
\text { death after } 20 \text { years }\end{array}$ \\
\hline Lamovec $^{8}$ & 1994 & 20 & 1.2 & Subareolar & - & $\begin{array}{l}\text { Modified radical } \\
\text { mastectomy }\end{array}$ & Well, 1 year \\
\hline Present case & 1998 & 66 & $3.0 \times 3.0 \times 2.6$ & Subareolar & + & $\begin{array}{l}\text { Modified radical } \\
\text { mastectomy }\end{array}$ & Well, 8 months \\
\hline
\end{tabular}

NE, not examined; NK, not known; ND, not described.

noma may arise in association with gynaecomastia. $^{11}$ Moreover, oestrogen and progesterone receptor assays of secretory carcinoma of the breast are generally negative, ${ }^{6}$ while an immunohistochemical study showed nuclear reactivity for oestrogen receptor in $89 \%$ of gynaecomastia specimens examined. ${ }^{12}$ Karl et al indicated that secretory carcinoma of

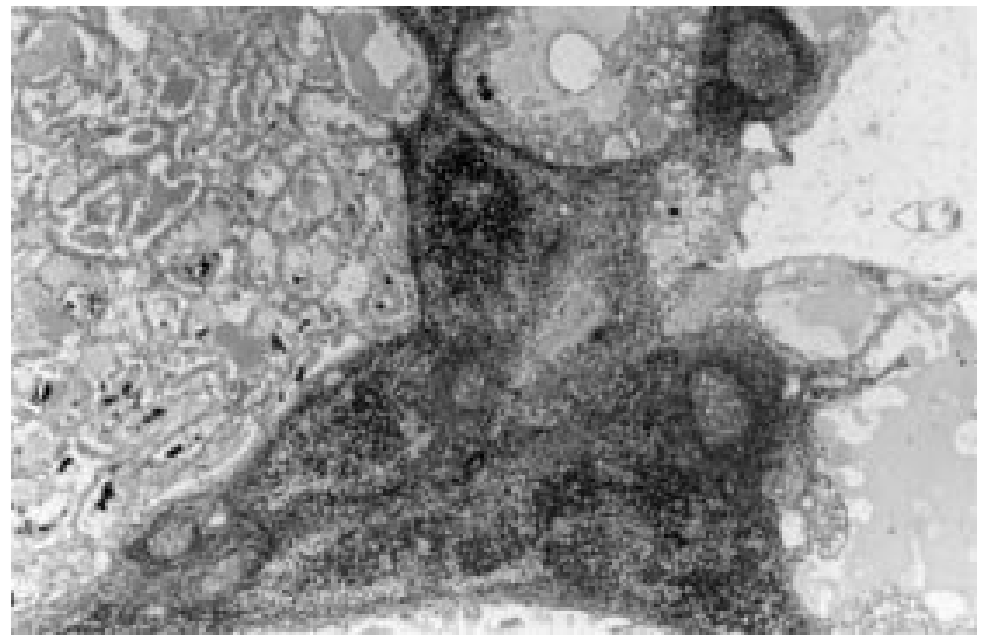

Figure 5 An axillary lymph node metastasis of secretory carcinoma. the breast does not develop in response to raised circulating oestrogen levels. ${ }^{5}$

From these findings, the breast carcinoma in our patient did not seem to be directly connected with gynaecomastia resulting from liver disease. Nevertheless, our case shows that secretory carcinoma of the breast can and rarely does occur in the elderly male.

1 McDivitt RW, Stewart FW. Breast carcinoma in children. JAMA 1966;195:388-90.

2 Tavassoli FA, Norris HJ. Secretory carcinoma of the breast. Cancer 1980;45:2404-13.

3 Schottenfeld D, Lilienfeld AM, Diamond H. Some observations on the epidemiology of breast cancer among males. Am F Public Health 1963;53:890-7.

4 Simpson JS, Barson AJ. Breast tumours in infants and Simpson JS, Barson AJ. Breast tumours in infants and
children: a 40 -year review of cases at a children's hospital.

Can Med Assoc f 1969;101:100-2.
5 Karl SR, Ballantine TVN, Zaino R. Juvenile secretory carciKarl SR, Ballantine TVN, Zaino R. Juvenile secretory
noma of the breast. F Pediatr Surg 1985;20:368-71.

6 Roth JA, Discafani C, O'Malley M. Secretory breast Roth JA, Discafani C, O'Malley M. Secretory bre
carcinoma in a man. Am f Surg Pathol 1988;12:150-4.

7 Krausz T, Jenkins D, Grontoft O, et al. Secretory carcinoma of the breast in adults: emphasis on late recurrence and metastasis. Histopathology 1989;14:25-36.

8 Lamovec J, Bracko M. Secretory carcinoma of the breast: light microscopical, immunohistochemical flow cytometric study. Mod Pathol 1994;7:475-9.

9 Pohar-Marinsek Z, Golouh R. Secretory breast carcinoma in a man diagnosed by fine needle aspiration biopsy. Acta Cytol 1994;38:446-50.

10 Botta G, Fessia L, Ghiringhello B. Juvenile milk protein secreting carcinoma. Virchows Arch (Pathol Anat) 1982; 395: 145-52.

11 Rosen PP. Breast pathology. Philadelphia: Lippincott-Raven, 1996:611-32.

12 Andersen J, Orntoft TF, Andersen JA, et al. Gynecomastia. Acta Pathol Microbiol Immunol Scand 1987;95:263-7. 